\title{
ASSESSMENT OF ENVIRONMENTAL AND SOCIO-ECONOMIC STRESS
}

\author{
Dieter Helm, Detlef Laußmann, Dieter Eis \\ Robert Koch Institute, Berlin, Germany
}

\begin{abstract}
SUMMARY
Since long, socio-economic status, often expressed as an index, is known to correlate with health outcomes like behavioural problems. We constructed a new index that encapsulated not only economic and social but also environmental stressors (ESES), using data of the German Health Interview and Examination Survey for Children and Adolescents, a nation-wide representative surveillance of 17,641 participants aged between 0 - 17 years. Different factors were selected to account for socio-economic stress (low parental education, low household income, low occupational status of the householder), domestic stress (living in large cities, exposure to tobacco smoke at home, crowded housing, mouldy walls), and prenatal stress (maternal smoking during pregnancy, drinking alcohol during pregnancy). Prior to the calculation of ESES, the different factors were multiplied by weights which were estimated by multivariate linear regression on a number of health outcomes. ESES was then used to predict emotional and social problems (SDQ scores). The resulting ORs were compared with those obtained for an established socio-economic index (SEI). ESES was superior to SEI as it could more clearly identify children and adolescents with emotional or social problems. Different types of stressors (i.e. socio-economic stress, domestic stress and prenatal stress) contributed independently to emotional and social problems.
\end{abstract}

Key words: domestic environment, prenatal environment, socio-economic index, SDQ, stressors

Address for correspondence: D. Helm, Robert Koch Institute, General-Pape-Straße 62-66, D-12101 Berlin, Germany. E-mail: helmd@ rki.de

\section{INTRODUCTION}

Much of the attention in epidemiological research is given to socio-economic status (SES) as this status is correlated to various disorders and health outcomes. Thus, SES is relevant to governmental policy concerning public health (1). Better understanding of the many relationships between a person's status and health outcomes will hopefully reveal important points for intervention and epidemiological research (2). Traditionally, SES is measured by education, income and occupation (3) although adverse environmental conditions are also related to higher prevalence and incidence of many disorders. Since a person's proximate environment is known to interact with their health (4) we aimed to include environmental parameters to yield a new approach towards a status which encapsulates economic, social and environmental variables.

From May 2003 to May 2006, the Robert Koch Institute conducted the nation-wide representative German Health Interview and Examination Survey for Children and Adolescents (KiGGS). Aim of this survey was to collect comprehensive data on the health status of children and adolescents aged 0 to 17 years. Participants were enrolled in two steps: first, 167 study locations (sample points) were chosen; second, subjects were randomly selected from the official registers of local residents. The survey involved questionnaires, physical examinations and tests, and a computer assisted personal interview performed by study physicians. A total of 17,641 subjects were surveyed - 8,985 boys and 8,656 girls. Response rate was $66.6 \%$; the proportion of non-participants was $5.3 \%(5)$.
The self-administered questionnaires considered developmental, health and health care issues relevant to children and adolescents. Apart from questions on sociodemographic variables, general somatic and mental health, sense of well-being, family structure, social environment and living conditions, the questionnaires comprised several specific items and assessment tools.

Among others, the Strengths and Difficulties Questionnaire (SDQ) was included to assess emotional and social problems of the 3-year-olds and older (6-7). SDQ comprised 25 items on psychological attributes, some positive and others negative. These were divided into 5 scales: 1 . emotional symptoms (5 items), 2. conduct problems (5 items), 3. hyperactivity/inattention (5 items), 4. peer relationship problems (5 items), and 5. prosocial behaviour (5 items). Additionally, a Total Difficulties score was calculated on base of 20 items. For all scales, outcome was classified as 'normal', 'borderline' or 'abnormal' according to the guidelines of SDQ (7). Since 'borderline' is not unequivocally indicative for emotional and social problems we confined ourselves to the evaluation of the 'normal' and 'abnormal' category.

It is well known that stress can influence the health of human beings (8). An important source of stress for children is their family's socio-economic situation (9). To assess this, KiGGS included standardised questions on both parents' educational and professional position, and the total income available to the family household (10). For the assessment of the socio-economic status of the volunteers the KiGGS study and its forerunners established and sucessfully used a special index: Winkler's socio-economic index or Winkler's SEI (11-12). 
Aim of this paper was to develop an index which accounts not only for the socio-economic features like Winkler's or others but includes also environmental conditions hopefully leading to an index of environmental and socio-ecological stress, which will be referred to as ESES. After the construction of ESES we tested this index against SDQ scales and compared results to those obtained for the traditional Winkler's SEI.

To include socio-economic stressors we followed Duncan's concept (3) and selected 1 . education of the mother, 2. education of the father, 3. household income and 4. occupational status of the householder. Low education (i.e. only elementary school or no professional education), low net household income (i.e. $<1,750 €$ per month, corresponding to the 20. percentile) and a low occupational status (i.e. farmer, unskilled or semi-skilled worker) were considered disadvantageous. We assumed that household income is an indicator of the capacity to consume valued goods, services and information, and that the parents' education is an indicator regarding the preference for prosocial and altruistic behaviour (rather than aggressive and escalating behaviour). Better educated people are also known to be more health-conscious than others (13). Our own data support this finding as families with a lower social status have a distinct and statistically significant lower rate of utilisation of child health reviews than families with a higher social status although these are free of charge (unpublished results). Occupational status is assumed to be a measure for prestige and the relative position in socially ranked hierarchies, where a high status should correspond to a high and influential position in the social network.

Selection of environmental stressors: To assess unfavourable domestic conditions we considered 1. living in large cities (i.e. $>100,000$ inhabitants), 2. exposure to tobacco smoke at home, 3. crowded housing conditions (i.e. $<21$ square metres per capita, corresponding to the 20. percentile), and 4. mouldy walls or ceilings in rooms where the child or adolescent customarily resides.

Living in large cities indicates more exposure to exhaust fumes, increased traffic noise, lack of green spaces in the vicinity and a greater risk to become victim of road accidents or acts of violance (14). Exposure to tobacco smoke at home is a risk factor for diseases of the respiratory system like bronchitis and asthma (15). Crowded housing conditions stand for little space where the child or adolescent can play, sleep, recreate and can undisturbedly do their homework (16). Mouldy walls or ceilings are unaesthetic and they indicate insanitary domestic conditions which, in turn, correspond to increased risks of diseases. When present in large quantities, mould spores have the potential to cause allergic reactions and even mycocis. Exposure to high levels of mycotoxins can lead to neurological problems and in some cases to death (17).

As interactions between child and (inner) environment have already been starting during pregnancy we also accounted for smoking tobacco and consuming alcohol by the mother during that time. Smoking or drinking alcohol (at least 'occasionally') were considered disadvantageous for the child since these conditions are considered harmful by many authors as they can cause intrauterine growth retardation and other adverse health outcomes like behavioural and psychosocial problems in childhood (18-19).

\section{MATERIALS AND METHODS}

\section{Construction of the ESES variables}

For all potential stressors the disadvantageous attribute was coded as ' 1 ' while the other attributes were coded as ' 0 '; i.e. poor paternal education $=1$; poor maternal education $=1$; low household income $=1$; low occupational status of the householder $=1$; living in large cities $=1$; exposure to tobacco smoke at home $=1$; crowded housing conditions $=1$; mouldy walls or ceilings at home $=1$; maternal smoking during pregnancy $=1$; maternal alcohol consumption during pregnancy $=1$.

\section{Estimation of the weighting factors for ESES variables}

Applying multiple linear regression analysis ESES variables were tested against a number of possible health outcomes $(n=12)$, like frequency of colds per year, parent-rated subjective health state of their children, and ADHS (attention deficit hyperactivity disorder) diagnosed by a physician or psychologist. For each health outcome, value was set to ' 1 ' when multiple regression analyses revealed a positive significant relationship. These values were added up to give the weighting factor.

(1) $\mathrm{w}=\Sigma \mathrm{v}_{\mathrm{i}}$, for $\mathrm{i}=1 \ldots 12$, where $v_{i}$ is the $\mathrm{i}$. health outcome value.

Thus, the possible maximum for each weighting factor was 12. Below we will refer to the weighting factors for the socioeconomic stressor as $w_{a}$ and for ecological stressors as $w_{b}$.

\section{Calculation of ESES}

The number of positive significant correlations between health variables and the stressors was used for weighting. Thus, ESES was computed according to the following formula:

(2) $\quad \operatorname{ESES}=\Sigma \mathrm{a}_{\mathrm{i}}{ }^{*} \mathrm{w}_{\mathrm{ai}}+\Sigma \mathrm{b}_{\mathrm{j}}{ }^{*} \mathrm{w}_{\mathrm{bj}}$, for $\mathrm{i}=1 \ldots 4$, and $\mathrm{j}=1 \ldots 6$, where $a_{i}$ is the $i$. socio-economic stressor and $b_{j}$ the j. ecological stressor; $w a_{i}$ is the weighting factor for the i. socio-economic stressor and $w b_{j}$ is the weighting factor for the $\mathrm{j}$. ecological stressor.

\section{Calculation of Winkler's SEI}

Winkler's socio-economic index (Winkler's SEI) was calculated as follows: Separate social status scores were computed for each of these components (11). The sum of the scores was calculated (ranging from 3-21). Scores were computed for each parent separately, and the higher score was used to define the child's social status. If parents were separated, the score of the main caregiver was used. Categories of social status were defined as low (3-8), medium (9-14), and high (15-21), as previously described (12).

\section{Transformation to a unique scale}

After the calculation we transformed ESES and Winkler's SEI to a range of $1 \ldots 25$. This was done to enable direct comparison since ESES and Winkler's SEI had different resulting ranges (please see the Results section), according to the following equation:

(3) $\mathrm{x}^{\mathrm{c}}=1+[(\mathrm{x}-l p v) /(\mathrm{hpv}-l o v)] * 24$; where $x$ is either ESES or Winkler's SEI before transformation, and $x^{\prime}$ after transformation; $l p v$ is lowest possible value, $h p v$ is highest possible value and lov is lowest observed value of the respective index. 
The sample was then divided into ESES quartiles and for each quartile the averages for age and ESES scores, the proportions of girls, individuals from families with low social status and immigrants were determined. Logistic regression was computed for the 5 SDQ scales and the Total Difficulties score as target variables with either ESES and Winkler's SEI as explanatory variables.

Next we tried to determine the effect of the different types of stressors: socio-economic, domestic conditions and prenatal stressors. We constructed 6 groups of participants: subjects without any of these stressors (i.e. no disadvantageous attributes at all), subjects who were exclusively exposed to prenatal stress, those who were exclusively exposed to domestic stress, those who were exclusively exposed to socio-economic stress; subjects with any combination of two types of stressors, and subjects who had disadvantageous attributes for all types of stressors investigated here. We will refer to these groups as 'no stress', 'prenatal stress', 'domestic stress', 'socio-economic stress', 'double stress' and 'triple stress'. For each group we determined the number of individuals showing abnormal scores on the SDQ scales.

Linear regression, logistic regression (calculation of ORs), transformation of ESES and Winkler's SEI and the calculation of descriptive statistics was all done with SPSS for Windows 14.

\section{RESULTS}

Prior to the calculation of ESES we determined the weighing factors for all components. None of the components reached the maximal possible value of 12 . Instead, we obtained the values of 5 (low maternal education), 4 (low paternal education), 6 (low household income), and 3 (low occupational state of the householder) for possible socio-economic stress factors; 1 (living in large cities), 9 (exposure to tobacco smoke at home), 4 (crowded housing), and 10 (mouldy walls or ceilings) for stress factors in the home environment; 9 (mother smoked during pregnancy) and 2 (mother drank alcohol during pregnancy) for prenatal stressors. As a result ESES ranged from 0 to 53 with a heavily skewed (log-normally shaped) distribution where frequency was highest for low values and lowest for high values (skewness $=1.03$, curtosis $=0.50$ ). In contrast, the results for Winkler's SEI ranged from 3 to 21 and were much closer to the shape of a normal distribution. The latter is quite understandable as Winkler's SEI aims to depict social stratification with a broad middle class and smaller numbers for the lower and upper class. Of the volunteers in the KiGGS sample ( $n=17,641) 45.4 \%$ were classified as having medium social status, whereas $27.5 \%$ and $27.1 \%$ were found to have low social status and high social status, respectively.
ESES could be calculated for 13,887 children and adolescents; the difference to the total KiGGS sample size arose because of the age restriction of the SDQ data (only 3- to 17-year-olds) and because of missing data for at least one of the 10 variables we used to construct ESES. Due to the semi-metric and non linear nature of ESES the quartiles did not comprise equal numbers of participants (Table 1), but ranged from 3,295 to 3,716 (expected value for each quartile was 3,472 ). The proportion of girls was approx. constant ( 49\%) and the mean age showed a moderate increase (from $\sim 9$ years to 10 years) indicating that there was a slight increment of disadvantageous attributes with age. In contrast, proportion of subjects from families with a low social status and proportion of immigrants both increased continuously with a much steeper increase for low social status than the proportion of immigrants.

Frequencies of disadvantageous attributes: out of all disadvantageous conditions we examined, low educational status of the father was most common and mouldy walls or ceilings was least frequent. In detail, we found the following frequencies: low educational status of the mother (28.1\%), low educational status of the father (35.8\%), low net household income (19.1\%), low occupational status of the householder (7.2\%), crowded housing (16.7\%), living in a large city (23.5\%), exposure to tobacco smoke at home (26.7\%), mouldy walls or ceilings (4.5\%), maternal smoking during pregnancy (at least 'occasionally'; 15.8\%), and maternal alcohol consumption during pregnancy (at least 'occasionally'; 14.5\%).

As for the differently stressed groups, $20.5 \%$ of the children and adolescents were classified to have no stress at all, $17.8 \%$ were exclusively socio-economically stressed, $14.7 \%$ were exclusively home stressed, 5.5\% were exclusively prenatally stressed, 30.0\% were doubly stressed, and $11.5 \%$ were triply stressed.

Different stressors contributed independently to ESES. Generally, lowest proportions of subjects with abnormal scores were found in the 'no stress' group (Table 2). Groups with 'socioeconomic stress' or 'domestic stress' comprised higher numbers of subjects with abnormal scores which were about in the same magnitude (e.g. $10.9 \%$ and $10.6 \%$ for the Peer Problems scale, respectively). The proportion of children and adolescents with abnormal scores in the 'prenatal stress' group was somewhat lower than in the 'socio-economic stress' and the 'domestic stress' group (e.g. 8.3\% for the Peer Problems scale). Most interestingly, effects of the different stressor types did not simply add up but rather seemed to be over-additive. For the Total Difficulties score we found $3.2 \%$ of the children and adolescents in the 'no stress' group scoring abnormally high. If this is considered a background value, the increase for those with exclusive 'socio-economic stress' was $3.1 \%$, for those with exclusive 'domestic stress' $1.9 \%$, and that

Table 1. Characterisation of the sample

\begin{tabular}{|l|c|c|c|c|c|c|c|}
\hline \multirow{2}{*}{ ESES quartiles } & \multirow{2}{*}{ No. } & \multicolumn{2}{|c|}{ Mean ESES score } & Age & Girls & Low social status & Immigrants \\
\cline { 3 - 8 } & & $\mathbf{x} \pm \mathbf{s}$ & Median & $\mathbf{x} \pm \mathbf{s}$ & $\%$ & $\%$ & $\%$ \\
\hline 1. Quartil (P 25) & 3,716 & $1.11 \pm 0.20$ & 1.00 & $8.8 \pm 5.1$ & 48.6 & 0.9 & 5.9 \\
\hline 2. Quartil (P 50) & 3,267 & $3.08 \pm 0.77$ & 2.88 & $9.1 \pm 5.2$ & 49.8 & 8.0 & 8.6 \\
\hline 3. Quartil (P 75) & 3,609 & $6.26 \pm 1.02$ & 5.71 & $9.9 \pm 5.1$ & 48.0 & 25.8 & 13.5 \\
\hline 4. Quartil (P 100) & 3,295 & $12.24 \pm 2.99$ & 11.35 & $10.0 \pm 5.0$ & 49.7 & 52.2 & 22.7 \\
\hline Total & 13,887 & $5.55 \pm 4.47$ & 4.76 & $9.6 \pm 5.1$ & 49.0 & 27.5 & 17.1 \\
\hline
\end{tabular}


Table 2. Effect of different stressors; the proportion of children and adolescents with abnormal high scores is given (In brackets: 95\% Cl)

\begin{tabular}{|c|c|c|c|c|c|c|}
\hline \multirow[b]{2}{*}{ SDQ scale } & \multirow{2}{*}{$\begin{array}{l}\text { No stress } \\
(n=2,847)\end{array}$} & \multirow{2}{*}{$\begin{array}{l}\text { Socio-economic stress } \\
\qquad(n=2,471)\end{array}$} & \multicolumn{2}{|c|}{ Environmental stress } & \multirow{2}{*}{$\begin{array}{l}\text { Double stress } \\
\qquad(n=4,169)\end{array}$} & \multirow{2}{*}{$\begin{array}{c}\text { Triple stress } \\
(n=1,592)\end{array}$} \\
\hline & & & $\begin{array}{l}\text { Domestic } \\
(n=2,046)\end{array}$ & $\begin{array}{c}\text { Prenatal } \\
(n=762)\end{array}$ & & \\
\hline Total difficulties & $\begin{array}{c}3.2 \% \\
(2.5 \%-4.1 \%)\end{array}$ & $\begin{array}{c}6.3 \% \\
(5.3 \%-7.5 \%)\end{array}$ & $\begin{array}{c}5.1 \% \\
(4.2 \%-6.3 \%)\end{array}$ & $\begin{array}{c}3.7 \% \\
(2.6 \%-5.3 \%)\end{array}$ & $\begin{array}{c}8.4 \% \\
(7.5 \%-9.4 \%)\end{array}$ & $\begin{array}{c}14.5 \% \\
(12.9 \%-16.3 \%)\end{array}$ \\
\hline Emotional symptoms & $\begin{array}{c}6.1 \% \\
(5.2 \%-7.2 \%)\end{array}$ & $\begin{array}{c}7.4 \% \\
(6.3 \%-8.7 \%)\end{array}$ & $\begin{array}{c}7.4 \% \\
(6.1 \%-8.9 \%)\end{array}$ & $\begin{array}{c}6.8 \% \\
(5.0 \%-9.2 \%)\end{array}$ & $\begin{array}{c}10.2 \% \\
(9.2 \%-11.2 \%)\end{array}$ & $\begin{array}{c}15.3 \% \\
(13.6 \%-17.3 \%)\end{array}$ \\
\hline Conduct problems & $\begin{array}{c}8.8 \% \\
(7.7 \%-10.1 \%)\end{array}$ & $\begin{array}{c}12.8 \% \\
(11.4 \%-14.4 \%)\end{array}$ & $\begin{array}{c}12.9 \% \\
(11.4 \%-14.5 \%)\end{array}$ & $\begin{array}{c}12.3 \% \\
(9.6 \%-15.5 \%)\end{array}$ & $\begin{array}{c}16.2 \% \\
(15.2 \%-17.3 \%)\end{array}$ & $\begin{array}{c}25.4 \% \\
(23.3 \%-27.7 \%)\end{array}$ \\
\hline Hyperactivity & $\begin{array}{c}4.7 \% \\
(3.8 \%-5.8 \%)\end{array}$ & $\begin{array}{c}7.3 \% \\
(6.2 \%-8.5 \%)\end{array}$ & $\begin{array}{c}5.3 \% \\
(4.2 \%-6.7 \%)\end{array}$ & $\begin{array}{c}6.0 \% \\
(4.2 \%-8.5 \%)\end{array}$ & $\begin{array}{c}9.0 \% \\
(8.1 \%-9.9 \%)\end{array}$ & $\begin{array}{c}14.0 \% \\
(12.5 \%-15.6 \%)\end{array}$ \\
\hline Peer problems & $\begin{array}{c}7.2 \% \\
(6.3 \%-8.2 \%) \\
\end{array}$ & $\begin{array}{c}10.9 \% \\
(9.5 \%-12.5 \%)\end{array}$ & $\begin{array}{c}10.6 \% \\
(9.2 \%-12.2 \%)\end{array}$ & $\begin{array}{c}8.3 \% \\
(6.1 \%-11.4 \%)\end{array}$ & $\begin{array}{c}13.0 \% \\
(11.8 \%-14.3 \%)\end{array}$ & $\begin{array}{c}16.6 \% \\
(14.8 \%-18.6 \%)\end{array}$ \\
\hline Prosocial behaviour & $\begin{array}{c}3.0 \% \\
(2.3 \%-3.8 \%)\end{array}$ & $\begin{array}{c}3.6 \% \\
(2.8 \%-4.7 \%)\end{array}$ & $\begin{array}{c}3.1 \% \\
(2.3 \%-4.1 \%)\end{array}$ & $\begin{array}{c}2.5 \% \\
(1.6 \%-4.0 \%)\end{array}$ & $\begin{array}{c}3.9 \% \\
(3.4 \%-4.5 \%)\end{array}$ & $\begin{array}{c}5.0 \% \\
(4.0 \%-6.2 \%)\end{array}$ \\
\hline
\end{tabular}

for those with exclusive 'prenatal stress' was $0.5 \%$. In contrast to the resulting total $(3.2 \%+3.1 \%+1.9 \%+0.5 \%=8.7 \%)$ the 'triple stress' group had $14.5 \%$ participants with abnormal high scores. Thus, the quotient between the observed proportion and calculation was 1.67. The average quotient for all SDQ scales was 1.45 indicating synergism between the three stressor types of $45 \%$ over expectation. Average quotient for the synergism of any two pairs of stressor types was 1.15 when compared to the observed proportion with abnormal values in the 'double stress' group.

Except for Winkler's SEI as predictor and Prosocial Behaviour scale as dependent variable all ORs obtained were statistically significant. It was however interesting to note, that ESES yielded universally higher ORs than Winkler's SEI (see Fig. 1). In consequence, an ESES of 5 stood for a $53 \%$ probability increase for abnormal values on the Emotional Symptoms scale whereas a Winkler's SEI of 5 stood for a 32\% probablitity increase (OR=1.53; 95\% CI 1.42-1.65 and OR=1.32; 95\% CI 1.26-1.43, respectively). For the Conduct Problems scale the corresponding probability increased from 34\% (Winkler's SEI; OR=1.34;

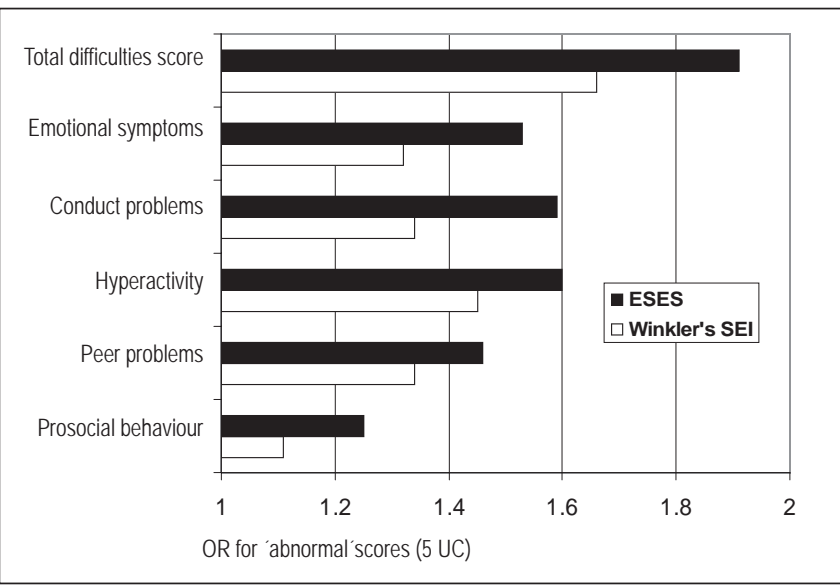

Fig. 1. Comparison of Winkler's SEI and ESES. Please note that the ORs are given for 5 units of change (UC = units of change).
95\% CI 1.28-1.45) to 59\% (ESES; OR=1.59; 95\% CI 1.49-1.70) - almost a duplication.

\section{DISCUSSION}

Social status (as expressed by Winkler's SEI) and ESES are positively and significantly correlated; Spearman's rho was 0.605 ( $p<0.001$ ). As ESES is basically sharing information with Winkler's SEI, this finding was not a surprise. Moreover, social status and environmental burden seem to been interlinked. Strong associations between indicators of socio-economic status (SES) and environmental exposures were recently reported by Hoffmann et al. (20). Children of immigrants or of parents with poor schooling and occupational training were more likely to be exposed to environmental tobacco smoke (ETS), high concentration of TSP (total suspended particulate matter) or to live at homes which were damp and/or situated less than $10 \mathrm{~m}$ from a busy road.

Proportion of subjects with immgration background increased with ESES because low social status is a confounder for immigration as immigration to Germany predominantly concerns people with low qualification, low income and poor (if any) occupational positions like labour immigrants, asylum seekers and refugees (21). KiGGS data confirm this correlation between low social status and immigration as $53.7 \%$ of the immigrants had low social status, $36.3 \%$ had medium social status and only $10 \%$ had high social status.

When aiming to predict emotional and behavioural problems with ESES or Winkler's SEI we found that ESES yielded universally higher ORs than Winkler's SEI. Therefore, we consider ESES better suited to identify children and adolescents with emotional or behavioural problems than Winkler's SEI. In case of the SDQ Prosocial Behaviour scale ESES was unequivocally superior to Winkler's SEI as ESES could identify children and adolescents with abnormal (risky) scores, i.e. with a tendency to non-prosocial behaviour, whilst Winkler's SEI failed to do so.

Since a synergistic effect was observed we can assume that each stressor type provides its own contribution to the emergence 
of emotional or behavioural problems to which their effects do not just add up but interact over-additively. This seems to be true for the interaction of two stressor types (like socio-economic stress and domestic stress) as well as for the interaction of three stressors. If there are three stressing conditions instead of two the proportion of children and adolescents will increase once again over expectation.

As for the reasons for that synergism we are obliged to speculate. Like in toxicology, where different toxins are known to cause independently adverse effects on different organs, biochemical pathways or cellular components, which can amplify each other, we assume that different stressors can cause different adverse effects on different aspects of the mind which will act over-additively. In consequence, that would mean that, when a child was already exposed to e.g. prenatal stress, we should aim and try to keep additional stressors away from them.

Outlook: We aim to extend ESES in regard to other potential stressors like e.g. overweight, increased TV watching, playing computer games or other reasons for the lack of exercise (22) and divorce of the parents (23) which are known to possibly induce distress in affected children and youths.

\section{Acknowledgements}

This work was supported by the German Federal Ministry of Health; and the German Federal Ministry of Education and Research. The authors are indebted to all who participated in KiGGS, and to their parents, for filling in the questionnaires and answering our questions. We also wish to thank the Mayors and authorities of the 167 communities for their endorsement and help.

\section{REFERENCES}

1. Oakes JM, Rossi PH. The measurement of SES in health research: curren practice and steps toward a new approach. Soc Sci Med. 2003 Feb;56 (4):769-84.

2. Taylor SE, Repetti RL, Seeman T. Health psychology: what is an unhealthy environment and how does it get under the skin? Annu Rev Psychol. 1997;48:411-47.

3. Duncan OD. A socioeconomic index for all occupations. In: Reiss AJ Jr, editor. Occupations and social status. New York: Free Press;1961. p. 109-38.

4. Woodruff TJ, Axelrad DA, Kyle AD, Nweke O, Miller GG, Hurley BJ Trends in environmentally related childhood illnesses. Pediatrics. 2004 Apr;113(4 Suppl):1133-40.

5. Kurth BM, Kamtsiuris P, Hölling H, Schlaud M, Dölle R, Ellert U, et al. The challenge of comprehensively mapping children's health in a nation-wide health survey: design of the German KiGGS-Study. BMC Public Health. 2008 Jun 4;8:196.

6. Goodman R. The extended version of the Strengths and Difficulties Questionnaire as a guide to child psychiatric caseness and consequent burden. J Child Psychol Psychiatry. 1999 Jul;40(5):791-9.
7. Goodman R, Ford T, Simmons H, Gatward R, Meltzer H. Using the Strengths and Difficulties Questionnaire (SDQ) to screen for child psychiatric disorders in a community sample. Br J Psychiatry. 2000 Dec;177: 534-9.

8. Erikson R, Torssander J. Social class and cause of death. Eur J Public Health. 2008 Oct;18(5):473-8.

9. du Prel X, Krämer U, Behrendt H, Ring J, Oppermann H, Schikowski T, et al. Preschool children's health and its association with parental education and individual living conditions in East and West Germany. BMC Public Health. 2006 Dec 28;6:312.

10. Jöckel KH, Babitsch B, Bellach BM, Bloomfield K, Hoffmeyer-Zlotnik J, Winkler J, et al. Measurement and quantification of socio-demographic features in epidemological studies. In: Ahrens W, Bellach BM, Jöckel $\mathrm{KH}$, editors. Measurement of socio-demographic features in epidemology. RKI-Schriften. München: MMV Medizin Verlag; 1998. p. 7-38. (In German.)

11. Winkler J. The measurement of social status in the health surveys of DHP by means of an index. In: Ahrens W, Bellach BM, Jöckel KH, editors. Measurement of socio-demographic features in epidemology. RKI-Schriften. München: MMV Medizin Verlag; 1998. p. 69-74. (In German.)

12. Winkler J, Stolzenberg H. Social class index in the Federal Health Survey. Gesundheitswesen. 1999 Dec;61 Spec No:S178-83. (In German.)

13. Ross CE, Wu CL. The links between education and health. Am Sociol Rev. 1995;60(5):719-45.

14. Robin M, Matheau-Police A, Couty C. Development of a scale of perceived environmental annoyances in urban settings. J Environ Psychol. 2007 Mar;27(1):55-68.

15. World Health Organization. International consultation on Environmental Tobacco Smoke (ETS) and child health. Geneva: WHO; 1999.

16. Chaudhuri N. Child health, poverty and the environment: the Canadian context. Can J Public Health. 1998 May-Jun;89 Suppl 1:S26-30, S2833.

17. Institute of Medicine. Damp indoor spaces and health. Washington, DC: National Academies Press; 2004.

18. Nordentoft M, Lou HC, Hansen D, Nim J, Pryds O, Rubin P, et al. Intrauterine growth retardation and premature delivery: the influence of maternal smoking and psychosocial factors. Am J Public Health. 1996 Mar;86(3):347-54.

19. Spohr HL, Willms J, Steinhausen HC. Prenatal alcohol exposure and longterm developmental consequences. Lancet. 1993 Apr 10;341(8850):90710.

20. Hoffmann B, Kolahgar B, Rauchfuss K, Eberwein G, Franzen-Reuter I, Kraft M, et al. Childhood social position and associations between environmental exposures and health outcomes. Int J Hyg Environ Health. 2009 Mar;212(2):146-56.

21. Wingen M. Immigration to the Federal Republic of Germany as a demographic and social problem. Int Migr Rev. 1995;29(3):710-21.

22. Bathrellou E, Lazarou C, Panagiotakos DB, Sidossis LS. Physical activity patterns and sedentary behaviors of children from urban and rural areas of Cyprus. Cent Eur J Public Health. 2007 Jun;15(2):66-70.

23. Serdeva S, Tzvetkov D, Manolova A. Family and social determinants of school maladjustment in students with emotional disturbances and behavioral disorders from recovery schools in Bulgaria. Cent Eur J Public Health. 1998 Nov;6(4):280-3. 